\title{
HR Professionals' Intention to Adopt and Use of Artificial Intelligence in Recruiting Talents
}

\author{
Mohammad Sarwar Alam ${ }^{1 *}$, Tohid-Uz-Zaman Khan², Sanjib Sutra Dhar ${ }^{3}$, Kazi Sirajum \\ Munira ${ }^{4}$
}

\footnotetext{
${ }^{1}$ Assistant Professor, Department of Management, University of Chittagong, Bangladesh 4331

${ }^{2}$ Lecturer, Department of Accounting, University of Chittagong, Bangladesh 4331

${ }^{3}$ Assistant Professor, Department of Accounting, University of Chittagong, Bangladesh 4331

${ }^{4}$ Lecturer, Department of Management, University of Chittagong, Bangladesh 4331

*Corresponding Email: alam.sarwar@cu.ac.bd
}

DOI: https://doi.org/10.38157/business-perspective-review.v2i2.122

Citation: Alam, M. S., Khan, T., Dhar, S. S. \& Munira, K. S. (2020). HR Professionals' Intention to Adopt and Use of Artificial Intelligence (AI) in Recruiting Talents. Business Perspective Review 2(2), 15-30. DOI: https://doi.org/10.38157/businessperspective-review.v2i2.122

\section{Research Article}

\begin{abstract}
Purpose: The present study is an attempt to explore the antecedents of behavioral intention to use artificial intelligence (AI) in recruiting talents by the HR professionals in Bangladesh. Drawing on the principle of the unified theory of acceptance and use of technology (UTAUT), which was built on the premise of technology acceptance model, the theory of planned behavior, the theory of reasoned action, and so forth, the current study has been conducted in the context of Bangladesh.

Method: Building on the understanding of the deductive reasoning approach, the investigation followed the positivism paradigm via a quantitative research strategy. We collected 226 replies from the end-users of AI through a self-administrative survey. We used structural equation modeling (SEM) via SmartPLS.

Results: Henceforth, the results in the findings filmed that all the hypotheses were supported.

Implications: One of the important implications of the present study is the use of the intervention mentioned in this study for the manufacturing and service firms.

Limitation: The major limitation is the use of cross-sectional data which implies that future research must use both cross-sectional and longitudinal data for the generalizability of the observed findings.
\end{abstract}

Keywords: Artificial Intelligence, AI Adoption, HR professionals, Recruiting talents, Bangladesh.

\section{Introduction}

Artificial Intelligence (AI) is the new building block that can be vouched in Human Resource Management, particularly more beneficial and effective in case of recruiting talents. A formidable 
challenge in the workplace is recruiting the best talents along with managing the diversity (Upadhyay \& Khandelwal, 2018). The recruiting industry can meet this challenge with the help of using AI in their business processes like recruiting talents. Recruiters can easily get information on personality and suitability over the traditional resume and focus more on creative and strategic issues because AI is responsible to take care of repetitive and boring tasks. The recruitment process will have more speed, especially in hiring by utilizing a more productive relationship between machine and man.

The adoption of any new system is the biggest challenge for both organizations and employees. To avoid unconscious bias, AI is intelligently designed. Many preliminary sources of bias like gender, name, age, school attended, race, and religion can easily ignore through the help of an AI-powered system. One of the foremost challenges is the shortage of skills faced by the recruitment industry (Bullhorn, 2018). Already 38 percent of companies in the USA adopted AI in HR management and the remaining 62 percent expect to adopt within this year (Erickson, 2018). Experts are assuming that this new trend of adoption of AI may enhance productivity and employee motivation in the workplace. Organizations use artificial intelligence will upheaval the war of talent instead of decreasing it as firms battle to recruit potential candidates (Ropani, 2018).

Ascertaining the critical feature of AI, mentionable global companies namely Microsoft, Facebook, Google, IBM, Telsa Motors, Amazon, Nvidia, and Baidu have been continuously making a huge amount of investment (Freund, 2017; Nisar, 2018). There are enormous studies that have been conducted in developed countries on the adoption of $\mathrm{AI}$ in recruiting talents in different contexts. To date, a significant amount of empirical studies has been done on the adoption of AI at the organizational level (Aboelmaged, 2014; Yang, Sun, Zhang, \& Wang, 2015). (Gartner, 2017) reported that almost $59 \%$ of organizations are still at the stage of gathering data and the other $6 \%$ are already deployed AI. It is still not very clear how an enterprise can adopt AI through the formulation and implementation of its business strategy (Gartner, 2017).

Consequently, Bangladesh and all other developing countries around the globe need to perceive that new verity such as artificial intelligence to compete in the global marketplace (Alvi, 2019). From the report of (McGovern et al., 2018) the explained adoption of AI is very slow in Bangladesh as well as the rest of the world, and the reasons behind are the talent-gap, more concern over privacy, ongoing maintenance, integration capabilities, and limited proven applications. However, the successful adoption of this system will bring many benefits for the organizations and HR functions itself such as reducing the amount of time HR professionals spend on administrative tasks, reducing the burden of shared service centers and help desks by performing HR transactions and providing answers for routine queries, recruiting and retention, measuring return on investments and reducing bias in HR decision-making.

We have observed from the previous studies that, a few pieces of literature stand relating to the adoption of $\mathrm{AI}$ in the Human Resource (HR) field especially in recruiting talents by the firms in Bangladesh. Henceforth, the progressive interest in AI and lack of studies on addressing AI adoption are the core inspirations for conducting this research in the field of HR particularly in recruiting talents. Keeping the above-stated literature in our understanding, this paper aimed to address two research objectives and will give a platform for future researchers to contribute to this field.

RQ1. What are the important predictors of adopting Artificial Intelligence in recruiting talents by HR 
professionals in Bangladesh?

RQ2. What significance does UTAUT have in the adoption of Artificial Intelligence in recruiting talents?

\section{Literature review}

\subsection{Artificial intelligence}

Artificial intelligence (AI) is a comprehensive wing of computer science concerned with building smart machines capable of conducting tasks that typically require human intelligence (Builtin, 2019). AI-related machine learning and deep learning are creating a paradigm shift in every area of the tech-industry (Buzko et al., 2016). It enables us to make decisions based on priorities and tackle complexity and ambiguity (Singh \& Sagar, 2013). It is capable of performing human-like processes such as to adapt, learn, synthesize, correct as well as using of diverse data and these tasks are required for processing composite activities in organizations' business processes (Popenici \& Kerr, 2017). It has also ensured the opportunities to strengthen an effective and efficient governance system for any organization (Nasrallah, 2014). In the era of information technology, people are highly dependent on varieties of new technologies and accomplishing goals as well as flawlessly conduct everyday tasks by using these. AI can also be used by the employers to recruit talents through step by step such as sourcing, screening, matching, and assessing (Ideal, 2020). Employers also have the opportunity to achieve goals by adopting and successfully implementing AI in their respective organizations (Cremer, 2013) .

\subsection{UTAUT model and Adoption of AI}

The evaluation of acceptance of any new technology is frequently based on the models exist in the literature on technology acceptance. The factors that predict acceptance usually explain by these models (Sun \& Zhang, 2006; Venkatesh, Chan, \& Thong, 2012). The Technology Acceptance Model (TAM), Theory of Reasoned Action (TRA) which is known as the adaptation of psychological theory has been one of the most considerable models in the technology acceptance research(Davis, 1989; Fishbein, 1975; King \& He, 2006; Park, 2009). However, alongside its extensive use, TAM was found to predict less than $50 \%$ of cases of acceptance of any technology (Park, 2009; Venkatesh \& Davis, 2000). Therefore, (Venkatesh, Morris, Davis, \& Davis, 2003) proposed the UTAUT model on the basis of an in-depth analysis of literature on technology acceptance which ultimately helps to address and solve that weakness of TAM.

The UTAUT has become a well-liked choice in research as it is a unified model which blend a wide variety of variables from eight prominent theories including the TRA (Fishbein, 1975), the TAM (Davis, 1989; Davis, Bagozzi, \& Warshaw, 1989), the Motivational Model (MM) (Davis et al., 1989), the Theory of Planned Behavior (TPB) (Ajzen, 2011), the Decomposed Theory of Planned Behavior (DTPB) (Taylor \& Todd, 1995), the Model of PC Utilization (MPCU) (Thompson, Higgins, \& Howell, 1991), the Innovation Diffusion Theory (IDT) (Moore \& Benbasat, 1996), and the Social Cognitive Theory (SCT) (Compeau \& Higgins, 1995). This model consists of four fundamental determinants of technology acceptance such as performance expectancy, effort expectancy, social influence, and facilitating conditions. These models 
acceptance UTAUT is a technology acceptance model formulated by (Venkatesh et al., 2003) in "User acceptance of information technology: Toward a unified view". The goal of UTAUT is to explain the intention and behavior of the user to use an information system. Many researchers used this model with some modifications befitting the context of their studies and they got positive results (Chong, 2013). (Venkatesh et al., 2003) found that the UTAUT model could explain almost $70 \%$ of variance concerning behavioral intention while other models and theories could explain $17 \%$ to $53 \%$ of variance concerning behavioral intention using identical data. According to that finding, we can also assume that the UTAUT model is also helping to explain the acceptance of AI by HR professionals 70\% and more. So, this model is considered significantly helpful to interpret the intention of the users to accept any technology like AI. Through the adoption of AI using UTAUT employers will understand their human talents completely (Rishi Agarwal, 2017). Adoption of AI can improve acquiring, assessing, and recruiting new human talents in the organizations (Jacques Bughin, 2018). It helps employers to take strategic decisions and acquire the right talents at the right time.

\subsubsection{Performance Expectancy (PE) \& Intention to Use}

Performance Expectancy (PE) in the UTAUT model explains the behavioral intention of the endusers. It can be illustrated "the magnitude to which an end-user believes that the use of the given application program will assist to arrive at a particular solution or job performance" (Venkatesh et al., 2003). An individual may believe the performance ability of the newly adopted technology (Suki \& Suki, 2017). It resembles perceived usefulness, trust, job-fit, relative advantage, and outcome expectation from a given technology (Ahmad, 2014). In the early studies, the researcher has found a significant influence of performance expectancy on behavioral intention in different areas such a (J.-M. Kim, 2017) in healthcare, (M. Z. Alam, Hu, \& Barua, 2018) in m-health services and (Uddin, Alam, Mamun, Khan, \& Akter, 2020) in ERP. Hence, the performance expectancy of an individual can influence their intention to use new technology like AI in recruiting talents. From the above literature we can develop following hypothesizes:

H1: Performance expectancy has a positive influence on behavioral intention.

\subsubsection{Effort Expectancy (EE) \& Intention to Use}

Effort Expectancy is elucidated as "the degree of ease associated with the use of the system" (Venkatesh et al., 2003). The easy accessibility of technology tends to drive users, making them highly prepared to adopt the technology(Dwivedi et al., 2017; Oliveira, Faria, Thomas, \& Popovič, 2014). (Salloum \& Shaalan, 2018) suggested that user-friendliness in any system will surely increase the intention to use that particular system. Effort expectancy is considered to be a significant and effective predictor to adopt AI ( $\mathrm{Lu}, \mathrm{Hsu}, \& \mathrm{Hsu}, 2005)$. Prior researches found significant and positive relationships in case of effort expectancy in a different arena. The study of (Ghalandari, 2012) on mobile banking service stated users' intention to use technology becomes positive when they found a particular system requires less effort to use or operate. (Onaolapo \& Oyewole, 2018) found that effort expectancy towards the use of smartphones for 
mobile learning showed a significant positive relationship. Moreover, other findings also suggest direct influences of effort expectancy on users' intention to adopt a technology(Alalwan, Dwivedi, \& Williams, 2014; M. Z. Alam et al., 2018; Muraina, Osman, Ahmad, Ibrahim, \& Yusof, 2016; Ozturk, Bilgihan, Nusair, \& Okumus, 2016; Shareef, Dwivedi, Kumar, \& Kumar, 2017; Shittu, Gambari, \& Sule, 2013). From the above literature we can develop following hypothesizes:

H2: Effort expectancy has a positive influence on behavioral intention.

\subsubsection{Social influence \& Intention to Use}

Social influence is defined as the degree to which an individual believes that people surrounding them are important when he or she deciding to use the new system (Venkatesh et al., 2003). Technology adoption greatly relies not only on an individual belief but also on social influence (Youngberg, Olsen, \& Hauser, 2009). Affiliation and perceived popularity of new technology are the most influential among other social factors that have an impact on individuals' choice to use a technology (Amin, Hamid, Lada, \& Anis, 2008; D. Kim, Chun, \& Lee, 2014). Individuals' involvement with technology may be measured by social influence (Venkatesh et al., 2003; Venkatesh, Thong, Chan, Hu, \& Brown, 2011). (Tarhini, El-Masri, Ali, \& Serrano, 2016) found that individual undergoes through social pressure come out from their surrounding environments such as friends, relatives, supervisors, and so forth which also may influence intention to behave in a certain way. In a given context, intention to use AI is shaped and influenced by subjective norms and positive aspiration by the community (Zhou, 2011). Several researchers examined that social influence has a positive and significant influence on behavioral intention to use a technology (Arman \& Hartati, 2015; Phichitchaisopa \& Naenna, 2013; Zhang \& Gutierrez, 2007). There were mixed opinions about the social influence effect on behavioral intention to adopt technology such as sometimes we found absenteeism of the effect of social influence on behavioral intention to use of AI (Chatterjee \& Bhattacharjee, 2020). However, there were strong shreds of evidence we found from the above literature that said that social influence is also a strong predictor of adopting technology like AI. Therefore, based on the discussions, the following hypothesizes is developed:

H3: Social influence has a positive influence on behavioral intention.

\subsubsection{Facilitating Conditions (FC) \& Intention to Use}

Facilitating condition is another controlling factor of individuals' behavioral intention to use technology (Salloum \& Shaalan, 2018). It was explained as "the degree to which an individual believes that an organization and technical infrastructure exists to support the use of the system" (Venkatesh et al., 2003). Behavioral control and compatibility of the other models are the constituents of FC (Lee \& Lin, 2008). As an important variable FC plays a vital role to adopt and use technology by an individual and organizations (Chiu, Lee, Liu, \& Liu, 2012). Technical infrastructure or initial training to the users may help them to realize the system clearly to adopt AI systems under FC. A direct relation has been developed between facilitating conditions and behavioral intention (Mun, Jackson, Park, \& Probst, 2006; Venkatesh, Thong, \& Xu, 2012). (M. S. 
Alam \& Uddin, 2019) argued in their study that facilitating conditions have a significant impact on behavioral intention to adopt ERP. It is observed that facilitating conditions significantly influenced the behavioral intention in case of e-filling by US taxpayers (Schaupp, Carter, \& McBride, 2010). (M. Z. Alam et al., 2018) reported that facilitating conditions has a direct impact on behavioral intention to adopt $\mathrm{m}$-health services. From the above literature we can develop following hypothesizes:

H4: Facilitating conditions have a positive influence on behavioral intention.

\subsubsection{Intention to Use \& Actual Use of AI}

Intention to use $\mathrm{AI}$ is associated with a sense of assessing the strength of intention of an individual to perform a specific behavior (Fishbein \& Ajzen, 1977). Intention to use AI is an effective predictor of performing the actual activities in which that intention is expressed (Zhang \& Gutierrez, 2007). Intention acts as a mediating variable to perform the behavior in favor of that activity to which one's intention to use AI is expressed (Nasrallah, 2014). Several types of research suggest that behavioral intention is the most influential predictor of individuals' behavior. In their recent study, (M. S. Alam \& Uddin, 2019) identified a significant and positive effect of ERP intention on the actual use of ERP. (Chatterjee \& Bhattacharjee, 2020) in their findings argued that to adopt artificial intelligence in higher education there was a positive and significant impact of behavioral intention to actual use. Thus, in most UTAUT model behavioral intention depicts a significant influence on an individual decision on actual use of AI. From the above literature we can develop following hypothesizes:

H5: Behavioral intention has a positive influence on actual use

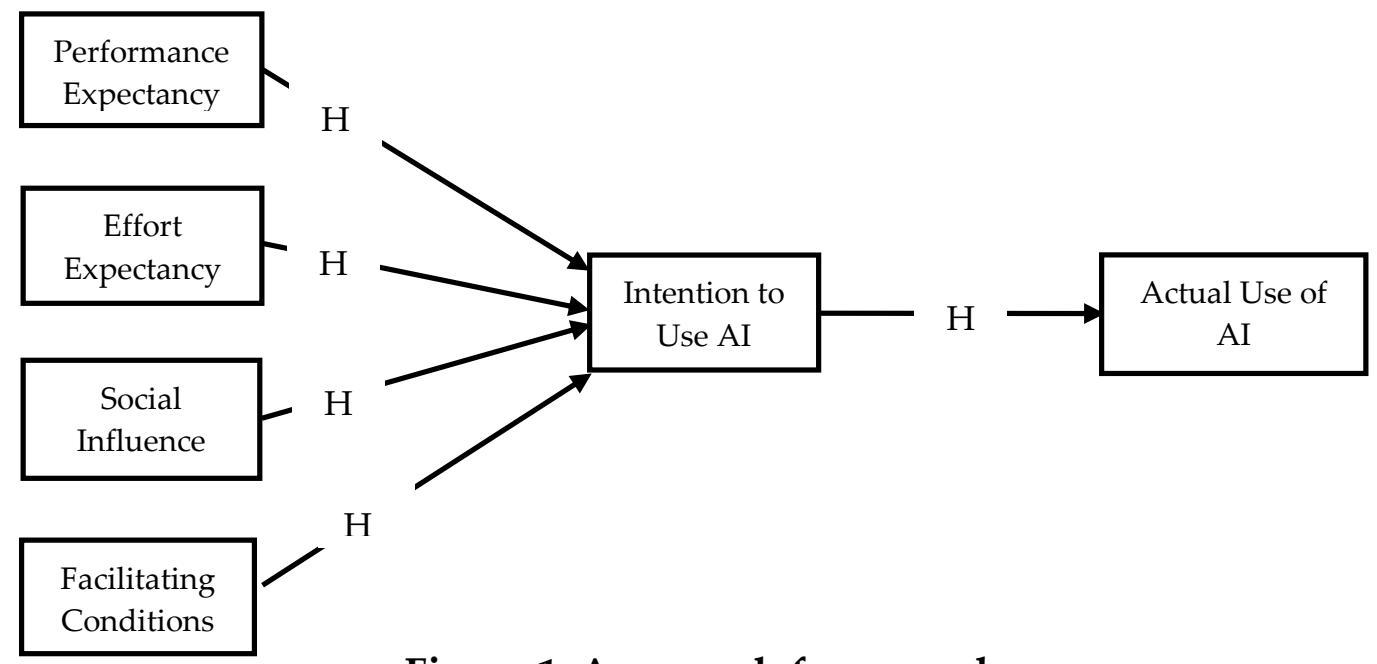

Figure 1: A research framework

\section{Research Methods}

\subsection{Data collection procedure}

A total of 350 self-administered questionnaires were distributed among employees working at different levels in a wide range of industries operating in Bangladesh. Self-administered 
questionnaire survey technique is chosen because it yields maximum response via email, physical visits, postal services while saves the cost and time of a survey (Zikmund, Babin, Carr, \& Griffin, 2010). We delivered the survey instruments to informants through a personal visit and also via email when respondents are unavailable during physical visits. We visited the respondents' facility at different times to distribute, remind, and the final collection of data. To prevent response- and social desirability -bias, we assured them that their identities would be kept private, and this research will only report on the general industrial scenarios. This assurance drives them to respond accurately while keeping their identities secret and saving their faces (MacKenzie \& Podsakoff, 2012). A total of 226 usable responses were received with a response rate of 64.57 percent which is seemed to be a standard response rate for yielding an accurate result (Azim, Fan, Uddin, Jilani, \& Begum, 2019). The raw data are then entered into SPSS 20.0 data editor for generating required statistical analysis. We also employed SmartPLS3, a second-generation partial least square analytical tool for the structural equation modeling for estimating the validity and reliability issues of the measures in this study (Howladar, Rahman, \& Uddin, 2018). We used structural equation modeling via SmartPLS3 in place of simple regression analysis because of the robustness and authenticity of the findings derived through the integrated model (Hair, Hollingsworth, Randolph, \& Chong, 2017).

\subsection{Sample characteristics}

Table 1 exhibits the demographic profile of the respondents including gender, age, academic qualifications, types of organization, the size of the organization, and their tenure experience. It reveals that the workplaces are male-dominated, with 80 percent men and 20 percent women. Additionally, the age distribution of the respondents delineates that most of them (65 percent) were in the range of 30-40 years followed by less than 30 years was 25 percent and over 40 years was only 10 percent.

Table 1. Demographic information $(n=226)$

\begin{tabular}{|llcc|}
\hline Variables & \multicolumn{1}{c}{ Characteristics } & Frequencies & Percentage \\
\hline Age & Less than 30 Years & 57 & 25.00 \\
\hline & 30 to 40 years & 146 & 65.00 \\
\hline & More than 40 & 23 & 10.00 \\
\hline Tenure & Less than 5 years & 103 & 46.00 \\
\hline & 5 to 10 years & 94 & 41.00 \\
\hline & More than 10 years & 29 & 13.00 \\
\hline Education & Bachelor & 43 & 19.00 \\
\hline & Master & 179 & 79.00 \\
\hline & Others & 4 & 2.00 \\
\hline Firms' size & Small & 20 & 9.00 \\
\hline & Medium & 84 & 37.00 \\
\hline & Large & 122 & 54.00 \\
\hline Gender & Male & 181 & 80.00 \\
\hline & Female & 45 & 20.00 \\
\hline Firms' type & Manufacturing & 157 & 70.00 \\
\hline & Service & 69 & 30.00 \\
\hline
\end{tabular}


The sample included respondents with different educational qualifications, such as bachelor, master, and others; where the most significant number (79 percent) of respondents had a master's degree. Regarding organization type, we observed the representation of respondents from the manufacturing 70 percent and service industries 30 percent. Finally, the maximum responses (91 percent) were received from large and medium organizations. Also, we observed that tenure from 1-10 years employees is the sheer portion (87 percent) of the total responses.

\subsection{Measurement tools}

The measurement tools, which were used here, were collected from prior studies. Survey instruments of performance expectancy (Venkatesh et al., 2003), effort expectancy (Venkatesh et al., 2003), social influence (Venkatesh et al., 2003; Venkatesh, Thong, et al., 2012), facilitating conditions (Venkatesh, Chan, et al., 2012; Venkatesh et al., 2003), behavioral intention (Venkatesh, Chan, et al., 2012), and actual use (Rajan \& Baral, 2015) were used. Some necessary amendments were made in terms of face validity to the items for their better fitness in the given context.

\section{Results and hypotheses testing}

\subsection{Analytical technique}

We used the multivariate data analytic technique to analyze the data because it engenders data using the whole model in an integrated manner (Hair Jr, Hult, Ringle, \& Sarstedt, 2016). Henceforth, PLS-based structural equation modeling (PLS-SEM), SmartPLS3 are used for three reasons (Hair et al., 2017). Firstly, it guarantees to estimate the model with any sample size. Second, the present study contains both direct effects and indirect effects, which can be measured simultaneously using PLS-SEM (Hair Jr et al., 2016). Another distinctiveness of PLSSEM is its capability to evaluate both the measurement model and the structural model for ensuring the genuineness of the results (M. S. Alam \& Uddin, 2019; Azim et al., 2019).

\subsection{Measurement model evaluation}

In our measurement model evaluation, we examined the constructs' reliabilities and validities underlying the study. Thereby, reliabilities are tested in Cronbach's alpha and composite reliability. Any score above 0.70 is recommended adequate (Hair et al., 2017; Hair Jr et al., 2016). Sores in Cronbach's alpha and composite reliability (table 2) ranged from 0.808 to 0.932 , which are within the cut-off value. Validities are in SEM underlies with convergent and discriminant validity.

Convergent validity refers to the clustering of its item into the same construct, whereas discriminant validity indicates the construct's distinctiveness from other constructs (Hair et al., 2017; Hair Jr et al., 2016). According to (Hair et al., 2017) convergent validities will be achieved when a construct's average variance extracted (AVE) exceeds 0.50. Table 2 reported that AVE ranged from 0.630 to 0.865 , which demonstrated that constructs' convergent validity is maintained. To test discriminant validity, (Fornell, 1981) posited that the square root of any construct's AVE must be higher than its correlation with other constructs. Likewise, table 2

22 Published by Research \& Innovation Initiative, 3112 Jarvis Ave, Warren, MI 48091, USA 
depicted the diagonal italicized scores (the square root of the related construct's AVE) are higher than scores beneath it. Thus, there is no concern about reliability and validity.

Table 2. Estimates on reliabilities and validities in a correlation matrix

\begin{tabular}{|c|c|c|c|c|c|c|c|c|c|c|c|c|}
\hline Variables & 1 & 2 & 3 & 4 & 5 & 6 & 7 & 8 & 9 & 10 & 11 & 12 \\
\hline \multicolumn{13}{|l|}{ Control variables } \\
\hline 01. Age & 1 & & & & & & & & & & & \\
\hline 02. Tenure & $.806^{* *}$ & 1 & & & & & & & & & & \\
\hline 03. Education & .116 & .036 & 1 & & & & & & & & & \\
\hline 04. Size & .048 & .082 & $.251^{* *}$ & 1 & & & & & & & & \\
\hline 05. Gender & .081 & .051 & -.009 & -.012 & 1 & & & & & & & \\
\hline 06. Firms' Type & -.117 & -.056 & $-.184^{* *}$ & $-.238^{* * *}$ & -.019 & 1 & & & & & & \\
\hline \multicolumn{13}{|l|}{ Latent variables } \\
\hline 07. AU & -.072 & -.092 & .101 & -.061 & .102 & $-.158^{*}$ & 0.930 & & & & & \\
\hline 08. EE & -.046 & -.056 & .004 & -.094 & -.061 & -.055 & 0.198 & 0.870 & & & & \\
\hline 09. FC & .013 & -.034 & .005 & -.031 & .001 & .048 & 0.270 & 0.285 & 0.912 & & & \\
\hline 10. IU & -.059 & .001 & -.011 & .090 & .050 & -.053 & 0.449 & 0.467 & 0.386 & 0.929 & & \\
\hline 11. PE & -.127 & -.073 & -.080 & -.034 & -.129 & -.015 & 0.266 & 0.461 & 0.245 & 0.444 & 0.794 & \\
\hline 12. SI & -.037 & -.017 & $-.134^{*}$ & -.090 & .092 & .114 & 0.213 & 0.382 & 0.265 & 0.354 & 0.222 & 0.906 \\
\hline \multicolumn{7}{|c|}{ Cronbach's Alpha } & 0.922 & 0.893 & 0.932 & 0.921 & 0.808 & 0.927 \\
\hline \multicolumn{7}{|c|}{ Composite Reliability } & 0.951 & 0.926 & 0.952 & 0.950 & 0.872 & 0.948 \\
\hline \multicolumn{7}{|c|}{ Average Variance Extracted (AVE) } & 0.865 & 0.758 & 0.831 & 0.864 & 0.630 & 0.820 \\
\hline \multicolumn{7}{|c|}{ Mean } & 3.670 & 3.624 & 3.563 & 3.589 & 3.831 & 3.469 \\
\hline \multicolumn{7}{|c|}{ Std. Deviation } & 0.847 & 0.802 & 0.923 & 0.960 & 0.707 & 0.897 \\
\hline
\end{tabular}

[AU. Actual use, EE. Effort expectancy, FC. Facilitating conditions, IU. Intention to use, PE. Performance expectancy, SI. Social influence]

\subsection{Structural model evaluation}

We evaluated the structural model using co-linearity testing, $\beta, p$-value, and $\mathrm{R}^{2}$. Co-linearity means that standardized regression weights among variables are not stable and subject to high standard errors. Figure 2 presented the results on the predicted paths along with their estimates also displayed the strength of the relationship in $\beta$ and the overall predictability of the model $\left(R^{2}\right)$. Subsequently, all the path coefficients are documented significant along with their significance levels. To investigate the strength of the $\mathrm{R}^{2}$, we used the references of (Cohen, 1977; Hair Jr et al., 2016). (Cohen, 1977) mentioned that $\mathrm{R}^{2}$ scores with $0.10,0.25$, and 0.30 are small, medium, and significant. Conversely, (Hair Jr et al., 2016) asserted that any score above $0.20\left(R^{2}\right)$ in a behavioral science discipline is satisfactory. Remarkably, figure 2 posited that $\mathrm{R}^{2}$ for both cases is above 0.20 . Thus, the strength of the paths and the overall predictability of the model is acceptable. 


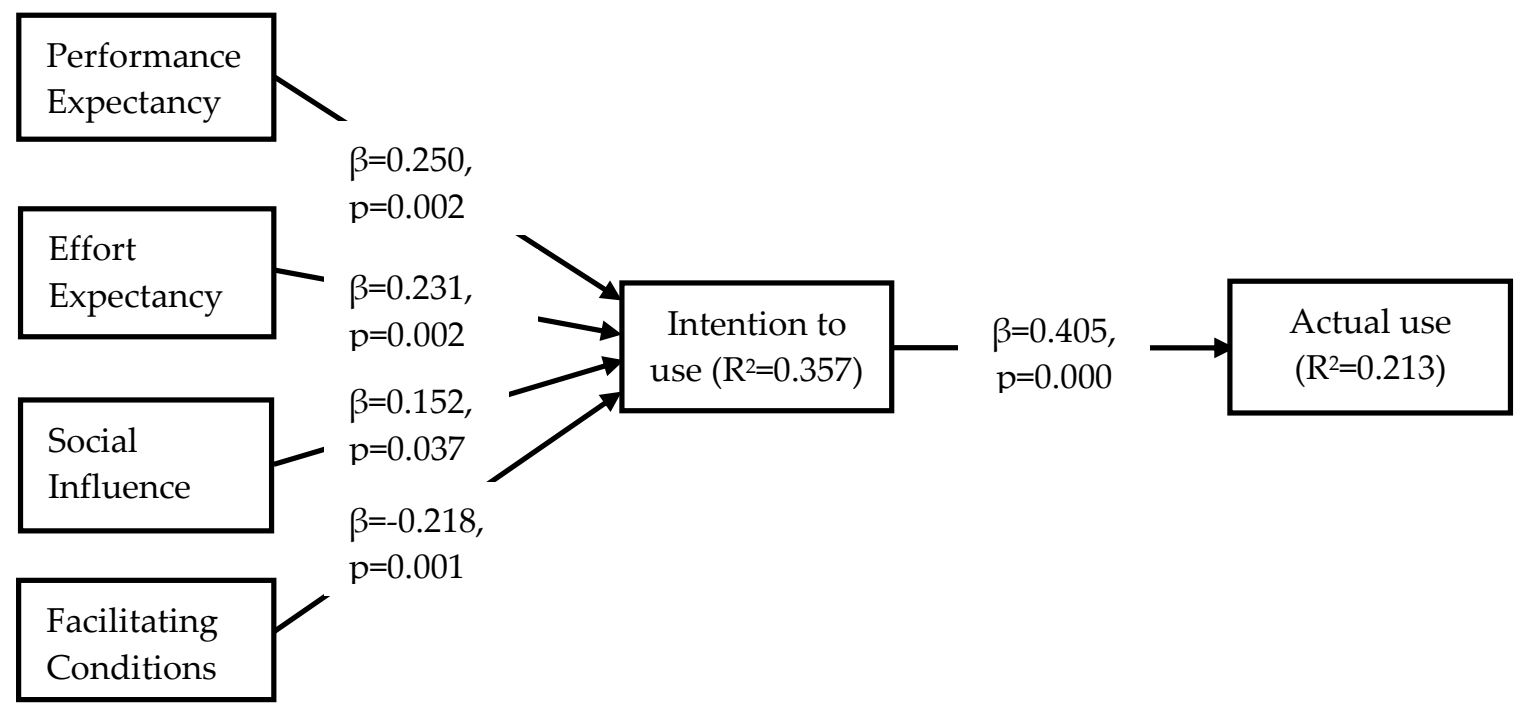

Fig. 2. The structural model with the path estimates

\section{Testing results of the hypothesis}

Results exposed in table 3 discovered that all the hypotheses (H1: $\beta=0.250 ; \mathrm{p}=0.002, \mathrm{H} 2: \beta=0.231$; $p=0.002$, H3: $\beta=0.152 ; p=0.037, \mathrm{H} 4: \beta=0.218 ; \mathrm{p}=0.001, \mathrm{H} 5: \beta=0.405 ; \mathrm{p}=0.000$ ) are supported. Consequently, the present research found all the hypotheses are significant. Therefore, we can conclude that performance expectancy, effort expectancy, social influence, and facilitating conditions positively influence users' behavioral intentions, and the direct effect of intention to use and actual use also found a highly significant.

Table 3. Result on hypotheses

\begin{tabular}{|ccccccc|}
\hline Hypothesis & Path & $\boldsymbol{\beta}$ & Standard Error & t-estimates & p-values & Decision \\
\hline H1 & PE $\rightarrow$ IU & 0.250 & 0.081 & 3.102 & 0.002 & Supported \\
\hline H2 & EE $\rightarrow$ IU & 0.231 & 0.074 & 3.107 & 0.002 & Supported \\
\hline H3 & SI $\rightarrow$ IU & 0.152 & 0.073 & 2.085 & 0.037 & Supported \\
\hline H4 & FC $\rightarrow$ IU & 0.218 & 0.066 & 3.321 & 0.001 & Supported \\
\hline H5 & IU $\rightarrow$ AU & 0.405 & 0.071 & 5.706 & 0.000 & Supported \\
\hline
\end{tabular}

\section{Discussion and Conclusion}

In this study, we used the UTAUT model to determine HR professionals' behavioral intention to use artificial intelligence in recruiting. We tested five hypotheses and all were found significant and consistent with the findings of (M. S. Alam \& Uddin, 2019; Casey \& Wilson-Evered, 2012; Kwateng, Atiemo, \& Appiah, 2019; Oliveira et al., 2014; Rozmi, Bakar, Hadi, \& Nordin, 2019; Uddin et al., 2020; Venkatesh et al., 2003; Wrycza, Marcinkowski, \& Gajda, 2017) where performance expectancy was found to have a positive impact on behavioral intention means it is recruiters believe performance will be enhanced if they use artificial intelligence in recruiting talents. Effort expectancy was found to have a positive impact on behavioral intension means the use of artificial intelligence will make their recruiting task easier than before. This study also found a positive impact of social influence on behavioral intention. This is not surprising as we 
know from the study of (Hofstede, 2001) cultural dimensions, people are always influenced by their peers, colleagues, mates, and relatives in a collective society. In that context, the users in Bangladesh will influence whether to use artificial intelligence or not are highly influenced by the people who are close to them. Finally, we also found facilitating conditions have a positive impact on behavioral intention which means infrastructural supports stuffs from an organization can highly motivate employees to use artificial intelligence at their workplace. According to the previous studies (M. S. Alam \& Uddin, 2019; Escobar-Rodríguez \& CarvajalTrujillo, 2014; Uddin et al., 2020; Venkatesh et al., 2003), the direct relationship between behavioral intention and actual use is also tested as highly influential as positive.

\section{Limitations, implications, and future research directions:}

The current study is an attempt to find out the factors influencing the adoption and the actual use of artificial intelligence in recruiting talents by HR professionals in the Bangladesh context. Even though this study contributes in numerous ways to enrich and enhance the literature as well as provides special insights by proposing the replacement of traditional recruitments it inherently contains some constraints that inhibit the generalization of the findings. First, we collected data from human resource professionals across the country who is working at different organizations both in manufacturing and service, which still lack industry comprehensiveness. Second, respondents are too young and most of them are working experience in between 1 to 10 years reveals that too little understanding of the real state of artificial intelligence adoption and the actual use of it. Henceforth, future researchers are expected to go for including more respondents with more working experience for getting a compact picture on the adoption of AI in Bangladesh. Third, the sample size and cross-sectional data prevent the findings from generalizability and causality. Thereby, we suggest using more responses in a longitudinal survey in a mixed-method design. Finally, the study on the adoption of AI in recruitment is in its infancy. It might not be adequate to generalize the findings based on research in Bangladesh. Therefore, we will recommend to future researchers to conduct more studies including other countries in South Asia, Asia Pacific, and the rest of the world as well as cross-culture settings to have a comprehensive sight of it.

Being the world's most densely populated country, Bangladesh is highly concentrating on rapid technological advancement in different industrial areas, automation, and control. In this country, AI is very recently caught eyes of the IT investors and government agencies that, successful implementation of this system can enhance productivity and makes this country more globally competitive. The digitalization of a country's economy not only drives innovation in its industries, but it also fuels domestic job opportunities, enabling faster economic growth. Developed countries like the US, UK, and Australia looking Bangladesh for their IT sourcing hub because of its lower risk and costs. This study will help the Bangladesh government to look more closely at those factors which are more contributing in AI adoption in this country as a result they will formulate such policies to attract investors and make a sustainable IT bases economy in the world. Moreover, IT investors, different organizations, and HR professionals 
from various sectors will get more useful knowledge by studying this paper and will able to use this knowledge in building the future for AI enable environment throughout the country.

\section{REFERENCES}

Aboelmaged, M. G. (2014). Predicting e-readiness at firm-level: An analysis of technological, organizational, and environmental (TOE) effects on e-maintenance readiness in manufacturing firms. International Journal of Information Management, 34(5), 639-651.

Ahmad, M. I. (2014). Unified theory of acceptance and use of technology (UTAUT): A decade of validation and development. Paper presented at the Proceedings of the 4th International Conference on ICT in our Lives (ISSN 2314-8942).

Ajzen, I. (2011). The theory of planned behaviour: Reactions and reflections: Taylor \& Francis.

Alalwan, A. A., Dwivedi, Y. K., \& Williams, M. D. (2014). Examining Factors Affecting Customer Intention And Adoption Of Internet Banking In Jordan. Paper presented at the UKAIS.

Alam, M. S., \& Uddin, M. A. (2019). Adoption and implementation of enterprise resource planning (ERP): An empirical study. Journal of Management and Research, 6(1), 1-33.

Alam, M. Z., Hu, W., \& Barua, Z. (2018). Using the UTAUT model to determine factors affecting acceptance and use of mobile health (mHealth) services in Bangladesh. Journal of Studies in Social Sciences, 17(2).

Alvi, D. A. (2019). Pakistan's place in artificial intelligence and computing. The Nation.

Amin, H., Hamid, M. R. A., Lada, S., \& Anis, Z. (2008). The adoption of mobile banking in Malaysia: The case of Bank Islam Malaysia Berhad (BIMB). International Journal of Business and Society, 9(2), 43.

Arman, A. A., \& Hartati, S. (2015). Development of user acceptance model for electronic medical record system. Paper presented at the 2015 International Conference on Information Technology Systems and Innovation (ICITSI).

Azim, M. T., Fan, L., Uddin, M. A., Jilani, M. M. A. K., \& Begum, S. (2019). Linking transformational leadership with employees' engagement in the creative process. Management Research Review.

Builtin. (2019). Artificial Intelligence, What is Artificial Intelligence? How Does AI Work?

Bullhorn. (2018). 2018 UK recruitment trends report: The industry's outlook for 2018.

Buzko, I., Dyachenko, Y., Petrova, M., Nenkov, N., Tuleninova, D., \& Koeva, K. (2016). Artificial Intelligence technologies in human resource development. Computer modeling and new technologies, 20(2), 26-29.

Casey, T., \& Wilson-Evered, E. (2012). Predicting uptake of technology innovations in online family dispute resolution services: An application and extension of the UTAUT. Computers in Human Behavior, 28(6), 2034-2045.

Chatterjee, S., \& Bhattacharjee, K. K. (2020). Adoption of artificial intelligence in higher education: a quantitative analysis using structural equation modeling. Education and Information Technologies, 1-21.

Chiu, Y.-T. H., Lee, W.-I., Liu, C.-C., \& Liu, L.-Y. (2012). Internet lottery commerce: an integrated view of online sports lottery adoption. Journal of Internet Commerce, 11(1), 68-80.

Chong, A. Y.-L. (2013). Predicting m-commerce adoption determinants: A neural network approach. Expert Systems with Applications, 40(2), 523-530.

Cohen, J. (1977). Statistical power for the behavioral sciences (revised edition): Academic Press, New York.

Compeau, D. R., \& Higgins, C. A. (1995). Computer self-efficacy: Development of a measure and initial test. MIS quarterly, 189-211.

Cremer, D., \& Bettignies, H. C. (2013). Pragmatic business ethics. The Leadership Maestro. Contents, 24(2), 64-67. doi: https://doi.org/10.1111/j.1467-8616.2013.00938.x.

Davis, F. D. (1989). Perceived usefulness, perceived ease of use, and user acceptance of information technology. MIS quarterly, 319-340.

Davis, F. D., Bagozzi, R. P., \& Warshaw, P. R. (1989). User acceptance of computer technology: a comparison of two theoretical models. Management Science, 35(8), 982-1003.

Dwivedi, Y. K., Rana, N. P., Janssen, M., Lal, B., Williams, M. D., \& Clement, M. (2017). An empirical validation of a unified model of electronic government adoption (UMEGA). Government Information Quarterly, 34(2), 
211-230.

Erickson, R. (2018). Infographic: Insights into a highly mature talent acquisition team. HR Daily Advisor.

Escobar-Rodríguez, T., \& Carvajal-Trujillo, E. (2014). Online purchasing tickets for low-cost carriers: An application of the unified theory of acceptance and use of technology (UTAUT) model. Tourism Management, 43, 70 88.

Fishbein, M. (1975). Ajzen, leek (1975), Belief, Attitude, Intention, and Behavior: An Introduction to Theory and Research. Reading, MA: Addison Wisley.

Fishbein, M., \& Ajzen, I. (1977). Belief, attitude, intention, and behavior: An introduction to theory and research.

Fornell, C. a. L., D. F. (1981). Evaluating Structural Equation Models with Unobservable Variables and Measurement Error. Journal of Marketing Research, 18(1), 39-50.

Freund, K. (2017). Five things to watch in AI and machine learning in 2017. Forbes.

Gartner. (2017). Applying Artificial Intelligence to Drive Business Transformation: A Gartner Trend Insight Report. 2-7.

Ghalandari, K. (2012). The effect of performance expectancy, effort expectancy, social influence, and facilitating conditions on acceptance of e-banking services in Iran: The moderating role of age and gender. Middle-East Journal of Scientific Research, 12(6), 801-807.

Hair, J., Hollingsworth, C. L., Randolph, A. B., \& Chong, A. Y. L. (2017). An updated and expanded assessment of PLS-SEM in information systems research. Industrial Management \& Data Systems, 117(3), 442-458. doi:10.1108/IMDS-04-2016-0130

Hair Jr, J. F., Hult, G. T. M., Ringle, C., \& Sarstedt, M. (2016). A primer on partial least squares structural equation modeling (PLS-SEM): Sage publications.

Hofstede, G. (2001). Culture's consequences: Comparing values, behaviors, institutions, and organizations across nations: Sage publications.

Howladar, M. H. R., Rahman, M. S., \& Uddin, M. A. (2018). Deviant Workplace Behavior and Job Performance: The Moderating Effect of Transformational Leadership. Iranian Journal of Management Studies, 11(1), 147-183. doi: 10.22059/ijms.2018.226143.672514

Ideal. (2020). Buyer's Guide: AI For Recruiting Software.

Jacques Bughin, J. S., James Manyika, Michael Chui, and Raoul Joshi. (2018). Notes from the AI frontier: Modeling the impact of AI on the world economy. McKinsey Global Institute.

Kim, D., Chun, H., \& Lee, H. (2014). Determining the factors that influence college students' adoption of smartphones. Journal of the Association for Information Science and Technology, 65(3), 578-588.

Kim, J.-M. (2017). Study on Intention and Attitude of Using Artificial Intelligence Technology in Healthcare. Journal of Convergence for Information Technology, 7(4), 53-60.

King, W. R., \& He, J. (2006). A meta-analysis of the technology acceptance model. Information \& management, $43(6), 740-755$.

Kwateng, K. O., Atiemo, K. A. O., \& Appiah, C. (2019). Acceptance and use of mobile banking: an application of UTAUT2. Journal of Enterprise Information Management.

Lee, V., \& Lin, S.-j. (2008). Podcasting acceptance on campus: an extension of the UTAUT model. DIGIT 2008 proceedings, 3.

Lu, H. P., Hsu, C. L., \& Hsu, H. Y. (2005). An empirical study of the effect of perceived risk upon intention to use online applications. Information management \& computer security.

MacKenzie, S. B., \& Podsakoff, P. M. (2012). Common method bias in marketing: Causes, mechanisms, and procedural remedies. Journal of retailing, 88(4), 542-555.

McGovern, S., Pandey, V., Gill, S., Aldrich, T., Myers, C., Desai, C., Balasubramanian, V. (2018). The new age: artificial intelligence for human resource opportunities and functions. Ey. com.

Moore, G. C., \& Benbasat, I. (1996). Integrating diffusion of innovations and theory of reasoned action models to predict the utilization of information technology by end-users Diffusion and adoption of information technology (pp. 132-146): Springer.

Mun, Y. Y., Jackson, J. D., Park, J. S., \& Probst, J. C. (2006). Understanding information technology acceptance by individual professionals: Toward an integrative view. Information \& Management, 43(3), 350-363. 
Muraina, I. D., Osman, W., Ahmad, A., Ibrahim, H., \& Yusof, S. (2016). Modeling the behavioural intention of broadband technology usage among teenagers: application of UTAUT Model. Asian Journal of Information Technology, 15(3), 593-601.

Nasrallah, R. (2014). Learning outcomes' role in higher education teaching. Education, business, and society: contemporary Middle Eastern issues.

Nisar, A. (2018). The pros and cons of artificial intelligence in Pakistan.

Oliveira, T., Faria, M., Thomas, M. A., \& Popovič, A. (2014). Extending the understanding of mobile banking adoption: When UTAUT meets TTF and ITM. International Journal of Information Management, 34(5), 689703.

Onaolapo, S., \& Oyewole, O. (2018). Performance expectancy, effort expectancy, and facilitating conditions as factors influencing smartphones use for mobile learning by postgraduate students of the University of Ibadan, Nigeria. Interdisciplinary Journal of e-Skills and Lifelong Learning, 14(1), 95-115.

Ozturk, A. B., Bilgihan, A., Nusair, K., \& Okumus, F. (2016). What keeps the mobile hotel booking users loyal? Investigating the roles of self-efficacy, compatibility, perceived ease of use, and perceived convenience. International Journal of Information Management, 36(6), 1350-1359.

Park, S. Y. (2009). An analysis of the technology acceptance model in understanding university students' behavioral intention to use e-learning. Journal of Educational Technology \& Society, 12(3), 150-162.

Phichitchaisopa, N., \& Naenna, T. (2013). Factors affecting the adoption of healthcare information technology. EXCLI Journal, 12, 413.

Popenici, S. A., \& Kerr, S. (2017). Exploring the impact of artificial intelligence on teaching and learning in higher education. Research and Practice in Technology Enhanced Learning, 12(1), 22.

Rajan, C. A., \& Baral, R. (2015). Adoption of ERP system: An empirical study of factors influencing the usage of ERP and its impact on the end-user. IIMB Management Review, 27(2), 105-117.

Rishi Agarwal, B. B., Peter Clarke, Murali Gandi, Grant Waterfall. (2017). What's now and what's next in human resources technology. PWC.

Ropani, R. (2018). Virtual reality and artificial intelligence: An unconventional guide to recruitment.

Rozmi, A. N. A., Bakar, M. I. A., Hadi, A. R. A., \& Nordin, A. I. (2019). Investigating the Intentions to Adopt ICT in Malaysian SMEs Using the UTAUT Model. Paper presented at the International Visual Informatics Conference.

Salloum, S. A., \& Shaalan, K. (2018). Factors affecting students' acceptance of e-learning system in higher education using UTAUT and structural equation modeling approaches. Paper presented at the International Conference on Advanced Intelligent Systems and Informatics.

Schaupp, L. C., Carter, L., \& McBride, M. E. (2010). E-file adoption: A study of US taxpayers' intentions. Computers in Human Behavior, 26(4), 636-644.

Shareef, M. A., Dwivedi, Y. K., Kumar, V., \& Kumar, U. (2017). Content design of advertisement for consumer exposure: Mobile marketing through short messaging service. International Journal of Information Management, 37(4), 257-268.

Shittu, A. T., Gambari, A. I., \& Sule, A. O. (2013). Students' attitude and behavioural intention on adoption of Internet for learning among Al-Hikmah University Students in Nigeria: A test of technology acceptance model. Malaysian Journal of Distance Education, 15(2), 89-107.

Singh, G., \& Sagar, A. M. D. (2013). An Overview of Artificial Intelligence, SBIT Journal of Sciences and Technology, 2 ( 1).

Suki, N. M., \& Suki, N. M. (2017). Determining students' behavioural intention to use animation and storytelling applying the UTAUT model: The moderating roles of gender and experience level. The International Journal of Management Education, 15(3), 528-538.

Sun, H., \& Zhang, P. (2006). The role of moderating factors in user technology acceptance. International journal of human-computer studies, 64(2), 53-78.

Tarhini, A., El-Masri, M., Ali, M., \& Serrano, A. (2016). Extending the UTAUT model to understand the customers' acceptance and use of internet banking in Lebanon. Information Technology \& People.

Taylor, S., \& Todd, P. A. (1995). Understanding information technology usage: A test of competing models. 
Information systems research, 6(2), 144-176.

Thompson, R. L., Higgins, C. A., \& Howell, J. M. (1991). Personal computing: toward a conceptual model of utilization. MIS quarterly, 125-143.

Uddin, M., Alam, M. S., Mamun, A. A., Khan, T.-U.-Z., \& Akter, A. (2020). A Study of the Adoption and Implementation of Enterprise Resource Planning (ERP): Identification of Moderators and Mediator. Journal of Open Innovation: Technology, Market, and Complexity, 6(1), 2.

Upadhyay, A. K., \& Khandelwal, K. (2018). Applying artificial intelligence: implications for recruitment. Strategic HR Review.

Venkatesh, V., Chan, F. K., \& Thong, J. Y. (2012). Designing e-government services: Key service attributes and citizens' preference structures. Journal of Operations Management, 30(1-2), 116-133.

Venkatesh, V., \& Davis, F. D. (2000). A theoretical extension of the technology acceptance model: Four longitudinal field studies. Management Science, 46(2), 186-204.

Venkatesh, V., Morris, M. G., Davis, G. B., \& Davis, F. D. (2003). User acceptance of information technology: Toward a unified view. MIS quarterly, 425-478.

Venkatesh, V., Thong, J. Y., Chan, F. K., Hu, P. J. H., \& Brown, S. A. (2011). Extending the two-stage information systems continuance model: Incorporating UTAUT predictors and the role of context. Information Systems Journal, 21(6), 527-555.

Venkatesh, V., Thong, J. Y., \& Xu, X. (2012). Consumer acceptance and use of information technology: extending the unified theory of acceptance and use of technology. MIS quarterly, 157-178.

Wrycza, S., Marcinkowski, B., \& Gajda, D. (2017). The enriched UTAUT model for the acceptance of software engineering tools in academic education. Information systems management, 34(1), 38-49.

Yang, Z., Sun, J., Zhang, Y., \& Wang, Y. (2015). Understanding SaaS adoption from the perspective of organizational users: A tripod readiness model. Computers in Human Behavior, 45, 254-264.

Youngberg, E., Olsen, D., \& Hauser, K. (2009). Determinants of professionally autonomous end user acceptance in an enterprise resource planning system environment. International Journal of Information Management, 29(2), 138-144.

Zhang, W., \& Gutierrez, O. (2007). Information technology acceptance in the social services sector context: An exploration. Social Work, 52(3), 221-231.

Zhou, T. (2011). Understanding mobile Internet continuance usage from the perspectives of UTAUT and flow. Information Development, 27(3), 207-218.

Zikmund, W. G., Babin, B. J., Carr, J. C., \& Griffin, M. (2010). Business Research Method (8th ed.). South-Western, Canada: Cengage Learning. Attribution (CC BY) license (http://creativecommons.org/licenses/by/4.0/).

\section{Appendix 1. Measurement tools}

\begin{tabular}{|c|c|}
\hline Measures & Items \\
\hline $\begin{array}{l}\text { Performance } \\
\text { expectancy }\end{array}$ & $\begin{array}{l}\text { In talent acquisition process - } \\
\text { (PE1) Use of software improves my productivity } \\
\text { (PE2) I would find the software useful in my job } \\
\text { (PE3) Using software saves my time } \\
\text { (PE4) If I use the software, I will increase my chances of getting a raise }\end{array}$ \\
\hline $\begin{array}{l}\text { Effort } \\
\text { expectancy }\end{array}$ & $\begin{array}{l}\text { (EE1) Learning to operate the software is also easy for me } \\
\text { (EE2) I would find the software easy to use } \\
\text { (EE3) Becoming skillful at using the software will be easy for me } \\
\text { (EE4) My job-related activities with AI-technology are clear and understandable }\end{array}$ \\
\hline
\end{tabular}




\begin{tabular}{|ll|}
\hline $\begin{array}{l}\text { Social } \\
\text { influence }\end{array}$ & $\begin{array}{l}\text { (SI1) People who are important to me think that I should use AI-based software } \\
\text { (SI2) People who affect/influence my behavior think that I should use AI-based software } \\
\text { (SI3) People whose opinions that I value prefer that I must use AI-based software } \\
\text { (SI4) In general, the organization has supported the use of AI-based software }\end{array}$ \\
\hline $\begin{array}{l}\text { Facilitating } \\
\text { conditions }\end{array}$ & $\begin{array}{l}\text { (FC1) I have the resources necessary to use AI-based software } \\
\text { (FC2) I have the knowledge necessary to use AI-software } \\
\text { (FC3) AI technology is not compatible with other available software/technologies I use } \\
\text { (FC3) I can get help from others if I have difficulties using AI software }\end{array}$ \\
\hline $\begin{array}{l}\text { Intention } \\
\text { use }\end{array}$ & $\begin{array}{l}\text { to } \\
\text { (IU1) I intend to continue using AI-based software in the future } \\
\text { (IU2) I will always try to use AI technology in my daily life } \\
\text { (IU3) I plan to continue to use the AI technology frequently }\end{array}$ \\
\hline Actual use & $\begin{array}{l}\text { (AU1) I have been using AI-based software for the last few weeks } \\
\text { (AU2) I am using this regularly now } \\
\text { (AU3) I am giving a lot of time in AI-based software applications }\end{array}$ \\
\end{tabular}

